\title{
Tidal currents and mixing in the Lake Maracaibo estuarine system*
}

\author{
ANA M. ANTORANZ ${ }^{1}$, J.L. PELEGRÍ1 ${ }^{1}$ and P. MASCIÁNGIOLI ${ }^{2}$ \\ ${ }^{1}$ Departamento de Física, Facultad de Ciencias del Mar, Universidad de Las Palmas de Gran Canaria, \\ Campus Universitario de Tafira, 35017 Las Palmas de Gran Canaria, Spain. \\ ${ }^{2}$ INTEVEP S. A., Centro de Investigación y Apoyo Tecnológico, Filial de Petróleos de Venezuela S. A., Los Teques, \\ Estado Miranda, Venezuela.
}

\begin{abstract}
SUMMARY: The Lake Maracaibo estuarine system is a cooscillating coupled ocean-lake system connected through a partially mixed estuary. In this paper we examine the low frequency movements $(\omega<0.1$ cycles/day) in the different water bodies within this system. The harmonic and rotary spectral analyses of velocity data indicates the importance of tidal forcing within the whole system and its interaction with winds and fresh water discharge. In particular, the results indicate the existence of dominant semi-monthly oscillations in Lake Maracaibo, likely of non-linear tidal origin, and suggest that vertical stratificaction plays an important role in controlling the three-dimensional structure of tidal currents.
\end{abstract}

Key words: estuarine system, tidal forcing, non-linear phenomena, stratification, mixing, Caribbean Sea.

\section{INTRODUCTION}

Any dynamical study of an estuarine system has to include both current and density distributions, simply because they are deeply interconnected. The relative forcing of river discharge and tidal range, together with the effect of winds, waves, and the geomorphology of the basin, will determine the level of vertical and horizontal stratification. In particular, stratification will be modified as the tidal current changes its strength through an individual tidal cycle or the neap-spring cycle, either by differential horizontal advection or through shear-induced mixing. This results in a rapid response of the estuarine system and makes it difficult to assess the principal factors responsible for the observed density

\footnotetext{
*Received June 5, 2000. Accepted November 14, 2000.
}

and current distributions with limited data sets. The existing stratification, on the other hand, will shape the instantaneous and mean currents. Stratification will enhance lateral advection but reduce vertical exchange. With strong vertical stratification, for example, the upper and lower layers may be rather uncoupled, the tidal wave having quite different amplitudes and phases.

Furthermore, tidal propagation is a highly nonlinear phenomenon, which results in higher harmonics and residual currents with pronounced spatial gradients. The effect of a non-linear mechanism on tidal constituents is to cause a modulation and/or distortion of these constituents, and to contribute towards a non-zero residual (zero-frequency) circulation (Parker, 1991). The important role of such a residual circulation in the net salt and sediment transport, as well as in pollutant flushing, within the 
estuary, demands an accurate description of the tidal circulation in estuaries (LeBlond, 1991).

The circulation-stratification feedback mechanism takes place in many different interacting ways, making the overall picture difficult to grasp and changing this picture from one estuary to another. The biological and chemical consequences of this interaction are, however, important. A stable density gradient may increase the horizontal dispersion and contribute to the entrance of salt, nutrients and pollutants into the estuary. Periodic and episodic vertical homogeneity is responsible for the replenishment of nutrients in the surface water, and oxygen in bottom waters, but may reduce the entrance of salt water. A subsequent period of stratification in a shallow water column may then lead to anoxic conditions, determining the vertical transfer of heat and light.

In this work we examine the propagation and modification of the tide through the Lake Maracaibo estuarine system, in particular investigating the spa- tial variations in the phase and amplitude of tidal currents as the estuary widens and the degree of stratification changes. It appears that the tide is greatly modified throughout the estuary, mainly because of the way the different constituents resonate with the different basins composing the system, but also because of the creation of higher tidal harmonics.

\section{The Lake Maracaibo estuarine system}

This is a coupled ocean-lake system connected through a partially mixed estuary, located on the Caribbean coast of Venezuela. The dynamic characteristics of this estuarine system result from the motion and interaction of sea and fresh water in its different water bodies: gulf, bay, strait, lake, and rivers (Fig. 1). The Gulf of Venezuela communicates at its southern boundary with El Tablazo Bay through three narrow inlets. El Tablazo Bay is a

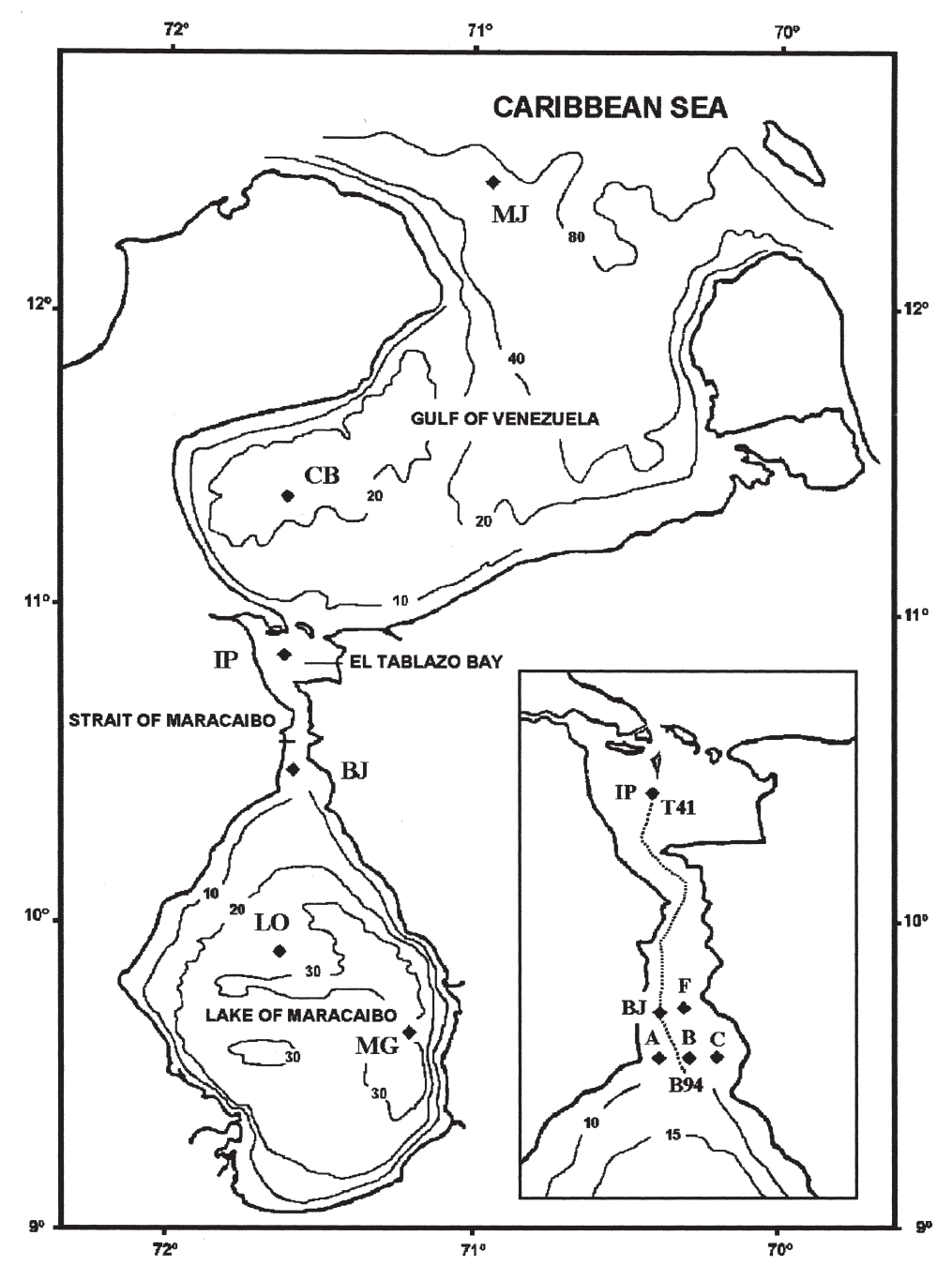

FIG. 1. - Map of the Lake Maracaibo estuarine system with the location of stations (black boxes) and transects (dotted line) used in this study. 
broad shallow embayment enclosed by barrier bars and islands and connected with the Strait of Maracaibo. El Tablazo Bay and the Strait of Maracaibo form a typical partially mixed estuary. The Lake of Maracaibo, a salt stratified water body, is located at the southern end of the Strait of Maracaibo. A navigation channel, that reaches depths of $15 \mathrm{~m}$, crosses the system from the Gulf to the Lake.

The circulation in the estuarine system is controlled by the conjunction of wind, river discharge, and tidal forcing. In this work we have concentrated on tidal forcing and its interaction with other processes. Tides are important in this system, being responsible for current reversals and salt-water intrusions. In particular, it is through tidal action that salt water enters El Tablazo Bay and the Strait of Maracaibo, where it mixes with the outflowing lake water. The resulting brackish mixture enters the lake at its northern end, and flows down along the bottom to form a saline hypolimnion (lower layer). The two-layer system is stirred up, with salt being transported up into the epilimnion (upper layer). The water of the epilimnion has a mean cyclonic circulation, with surface water escaping from the lake along the eastern shore. The relative importance of the forces responsible for the generation of the cyclonic circulation is not yet well known.

The precipitation on the Lake Maracaibo basin presents maximum values in October/November and April/May, and minimum values in February/March and July/August. The October/November maximum is greater than the April/May, while the February/March minimum is much lower than the July/August minimum. The surface water flows out along the Strait of Maracaibo and through El Tablazo Bay with velocities related to recent rainfall over the drainage basin, mixing with salt water introduced by tidal action from the Gulf of Venezuela.

The wind variability in the estuarine system depends on the northeastern trade winds and sealand breezes. The trade winds blow all year in this area, being more intense during the December-April period. The sea-land breezes present diurnal oscillations and predominate when the trade winds are less intense between May and November.

\section{Tidal forcing in the Lake Maracaibo estuarine system}

Tides in the Caribbean Sea are of mixed-diurnal type. The semi-diurnal tides, however, resonate in the Gulf of Venezuela because of its dimensions, and become dominant in the southern corner of the Gulf of Venezuela, within El Tablazo Bay, and in the Strait of Maracaibo. In Lake Maracaibo, because of its dimensions, the diurnal constituents again prevail. Thus, a major characteristic of the Lake Maracaibo estuarine system is that the tidal regime changes from mixed diurnal to semi-diurnal in its northern portion, to mainly semi-diurnal in its central region, and to diurnal in its southern extreme (Redfield et al., 1955; Redfield, 1961; Molines et al., 1989).

Redfield's (1961) and Molines and Fornerino's (1985) analyses for the semi-diurnal constituents show the existence of a nodal line in the northern end of the Lake, near La Salina, while an antinode is present in the central portion of El Tablazo Bay. The diurnal constituents have a node concurrent with the semi-diurnal antinode found in El Tablazo Bay. Tidal amplitudes within Lake Maracaibo are less than $3 \mathrm{~cm}$ at various frequency bands. Non-linear interaction in the Bay and the Strait, however, generates small but measurable overtides in the third and fourth diurnal bands, which have received little attention to date (Lynch et al., 1990).

\section{OBSERVATIONS AND METHODS}

During the 1980s and 1990s INTEVEP (Research and Development Center of Petróleos de Venezuela, S.A.) made a number of measurements and deployed current meter arrays at stations situated along the estuarine system. In this paper we analyze two different types of data set. First, the density data of two transects along the estuary, taken from El Tablazo Bay to the southern end of the Strait of Maracaibo during flood and ebb tide conditions. Second, the current meter data recorded at several stations during both high and low lake-runoff conditions. Specifically, we examine the current data from two stations in the Gulf of Venezuela, three stations along the main stem of the Strait, three stations across the entrance to Lake Maracaibo, and two stations in Lake Maracaibo. The location of the stations is shown in Figure 1, and the instrument and water bottom depths are given in Table 1 .

Hourly water velocity were obtained from 10 minutes average Aanderaa rotor current meter data. The data were harmonically analysed using a leastsquares technique. To investigate the structure of the tidal currents it is advantageous to use the clockwise and anticlockwise rotary components. This form of 
TABLE 1. - Stations in the Lake Maracaibo Estuarine System.

\begin{tabular}{lccc}
\hline $\begin{array}{l}\text { Station } \\
\text { designator }\end{array}$ & Location & $\begin{array}{c}\text { Station depth } \\
(\mathrm{m})\end{array}$ & $\begin{array}{c}\text { Instrument depth } \\
(\mathrm{m})\end{array}$ \\
\hline MJ & Gulf & 55 & 6.5 \\
CB & Gulf & 23 & 6.5 \\
IP & Bay & 12 & 4 \\
BJ & Strait & 11 & 4 \\
A & Strait & 7 & 4 \\
B & Strait & 13 & 4 and 7 \\
C & Strait & 10 & 4 and 9.5 \\
F & Strait & 10 & 4 \\
MG & Lake & 30 & 6.5 \\
LO & Lake & 27 & 2.5 \\
\hline
\end{tabular}

counter rotating vectors is basic to calculate the ellipse characteristics: semi-major (M) and semiminor $(\mathrm{m})$ axes, phase and orientation of the semimajor axis, and ellipticity $(\mathrm{m} / \mathrm{M})$. Ellipticity values range between 1 for anticlockwise rotation and -1 for clockwise rotation, with a zero value for linear currents. The orientation is measured anticlockwise from the east, a negative semi-minor axis indicating clockwise rotation. The number of constituents that may be found with the harmonic analysis depends on the length of the time series. The records from MJ, CB, IP, BJ, MG and LO stations are at least 26 days duration allowing the resolution of the neighboring tidal constituents $\mathrm{M}_{2}, \mathrm{~S}_{2}, \mathrm{~K}_{1}$, and $\mathrm{O}_{1}$, as well as upper harmonics constituents. However, the records from stations $\mathrm{A}, \mathrm{B}, \mathrm{C}$ and $\mathrm{F}$ are three days long, which only allows identification of the principal diurnal and semi-diurnal constituents. The results indicate high spatial variability of the tidal ellipses, both for the principal semi-diurnal/diurnal constituents and for the major non-linear constituents.

The high variability of the tidal ellipses led us to carry out a rotary analysis to examine the shape of the tidal ellipses and the tidal frequency energy distribution. The rotary analysis of currents involves the separation of the velocity vector for a specified frequency, $\omega$, into clockwise and anticlockwise rotating circular components with amplitudes $A^{-} \mathrm{y}$ $A^{+}$and relative phases $\theta^{-}, \theta^{+}$, respectively. Thus, instead of dealing with the amplitudes and phases of two Cartesian components we deal with the amplitudes and phases of two circular components $\left(A^{-}, \theta^{-}\right.$; $\left.A^{+}, \theta^{+}\right)$. The addition vector of these two oppositely rotating circular vectors causes the tip of the combined vector to trace out an ellipse over one complete cycle. The eccentricity of the ellipse, $e$, is determined by the relative amplitudes of the two components. Motions at frequency $\omega$ are circularly polarized if one of the two components is zero, rectilinear if both circularly polarized components have the same magnitude. The analysis of a current vector series in terms of two counter rotating vectors also provides information on some of the ellipse characteristics, such as the size of the semi-major and semi-minor axes, and the phase and orientation of the semi-major axis.

One important advantage of the rotary analysis is that many of the rotary properties, such as spectral energy, $S^{-}(\omega)$ and $S^{+}(\omega)$, and rotary coefficient, $r(\omega)$, are invariant under coordinate rotation, so are not affected by local steering of currents or by the local geomorphology. The sense of rotation of the vector about the ellipse is given by the rotary coefficient

$$
r(w)=\frac{S^{+}(w)-S^{-}(w)}{S^{+}(w)+S^{-}(w)}
$$

values of the rotary coefficient range from $r=-1$, clockwise motion, to $r=+1$, anticlockwise motion, with $r=0$ corresponding to unidirectional flow.

\section{RESULTS}

Several studies carried out in the Lake Maracaibo estuarine system indicate that the tide and tidal currents have high spatial (Redfield et al., 1955; Sutton et al., 1974; Parra-Pardi, 1983) and temporal variability (Masciangioli et al., 1984; Pelegrí et al., 1986, 1987, 1988). So far, however, most of the previously reported efforts have investigated the patterns of variation of the tidal elevation. Here we have compiled and analyzed current series from 10 stations in order to describe the main characteristics of the tidal currents and to identify the relative importance of tidal movements on the stratification and residual circulation

TABLE 2. - Tidal current regime as expressed in terms of the form factor ( 0 to 0.25 semi-diurnal; 0.25 to 1.5 mixed, mainly semidiurnal; 1.5 to 3.0 mixed, mainly diurnal; greater than 3.0 diurnal).

\begin{tabular}{lrrrrrl}
\hline Station & \multicolumn{3}{c}{ Tidal constituents } & $\begin{array}{r}\text { Factor form, F } \\
(\mathrm{cm} / \mathrm{s})\end{array}$ & Tidal regime \\
& $\mathrm{K}_{1}$ & $\mathrm{O}_{1}$ & $\mathrm{M}_{2}$ & $\mathrm{~S}_{2}$ & $\begin{array}{c}\left(\mathrm{O}_{1}\right) / \\
\left(\mathrm{M}_{2}+\mathrm{S}_{2}\right)\end{array}$ & \\
\hline MJ & 2.7 & 1.3 & 8.2 & 2.4 & 0.38 & Mixed semi-diurnal \\
CB & 4.6 & 3.1 & 11.5 & 1.6 & 0.59 & Mixed semi-diurnal \\
IP & 42.7 & 22.9 & 54.3 & 6.0 & 1.10 & Mixed semi-diurnal \\
BJ & 7.9 & 3.9 & 23.1 & 3.6 & 0.44 & $\begin{array}{c}\text { Mixed semi-diurnal } \\
\text { Mixed diurnal }\end{array}$ \\
LO & 1.3 & 1.1 & 1.0 & 0.5 & 1.60 & Mixed diurnal \\
MG & 1.1 & 0.4 & 0.5 & 0.5 & 1.50 & \\
\hline
\end{tabular}


within the estuary. The residual current is the nontidal part of the current, caused by processes different than the tidal force or tidal interactions in shallow water.

The tidal regime is commonly expressed in terms of a form factor, which quantifies the relative importance of the diurnal $\left(\mathrm{K}_{1}, \mathrm{O}_{1}\right)$ and semi-diurnal $\left(\mathrm{M}_{2}\right.$, $\mathrm{S}_{2}$ ) tidal constituents. Table 2 shows such a form factor for the major axis of the tidal ellipse as obtained from each station. The tidal currents change from mixed diurnal and semi-diurnal, when entering the system at its northern tip, to mainly semi-diurnal in its middle portion, and diurnal in the southern regions.

\section{Three dimensional current structure}

The vertical current structure was studied in February 1990 (dry season) with current meters simultaneously deployed at four moorings: A, B, C and $\mathrm{F}$ (Fig. 1). There were three moorings located across the entrance to Lake Maracaibo with one current meter in station A $(4 \mathrm{~m})$ and two current meters in both stations $B(4,7 \mathrm{~m})$ and $\mathrm{C}(4,9.5 \mathrm{~m})$. At all depths the current presents a northwesternsoutheastern oscillation, with the intensity of the oscillation decreasing with depth and its orientation turning East-West. In station F (4 m) further north, about $10 \mathrm{~km}$ away, the oscillation is mainly North-South, entirely following the orientation of the main channel.
Table 3 summarizes the ellipse parameters of the principal tidal constituent, $\mathrm{M}_{2}$, as obtained from the harmonic analysis of the data. For this constituent the ellipse rotation is clockwise at stations $\mathrm{A}$ and $\mathrm{F}$, at $4 \mathrm{~m}$ depth, and at station B, at $7 \mathrm{~m}$ depth. Nevertheless, it is anticlockwise in station B, at $4 \mathrm{~m}$ depth, and in station $\mathrm{C}$, at 4 and $9.5 \mathrm{~m}$ depths. In all cases, however, the tidal semi-diurnal ellipses show weak rotation $(0.002<\varepsilon<0.025$, anticlockwise; $-0.076<\varepsilon<-$ 0.050 , clockwise). These small ellipticity values indicate an unidirectional character of the currents, typical of a cooscillating tide.

The magnitude of the tidal ellipses in stations B, $\mathrm{C}$, and $\mathrm{F}$, at $4 \mathrm{~m}$ depth, varies between 42.1 and 48.6 $\mathrm{cm} / \mathrm{s}$. In station A, located in very shallow waters, the ellipses are over $20 \%$ larger. The magnitude of the tidal ellipse decreases with depth at all stations. The surface current is slightly out of phase in stations $\mathrm{A}, \mathrm{B}$, and C: $58.9^{\circ}, 72.6^{\circ}$, and $68.2^{\circ}$, respectively. At one single location the phase of the current changes slightly with depth: $72.6^{\circ}$ at $4 \mathrm{~m}, 67.9^{\circ}$ at $7 \mathrm{~m}$ (station B); $68.2^{\circ}$ at $4 \mathrm{~m}, 61.4^{\circ}$ at $9.5 \mathrm{~m}$ (station C). Likewise, the orientation of the tidal ellipse, as measured in degrees anticlockwise from the East, changes slightly between different stations and depths. These results are likely due to the different water response at each position, which is related to the local vertical and horizontal density stratification.

The rotary spectral analysis of current data from all stations shows that the semi-diurnal band is the most energetic. For example, at $4 \mathrm{~m}$ depth at sta-

TABLE 3. - Tidal ellipse characteristics of the $\mathrm{M}_{2}$ semi-diurnal constituent at stations A, B, C, and F (February 21 to 23, 1990). The ellipticity ranges from -1 , clockwise rotation, to 1 , anticlockwise rotation: $-1<\varepsilon<1$. The angle of orientation is measured anticlockwise from the east.

\begin{tabular}{lcccccc}
\hline Station & Depth $(\mathrm{m})$ & $\begin{array}{c}\text { Semi-minor axis, } \\
\mathrm{m}(\mathrm{cm} / \mathrm{s})\end{array}$ & $\begin{array}{c}\text { Semi-major axis, } \\
\mathrm{M}(\mathrm{cm} / \mathrm{s})\end{array}$ & $\begin{array}{c}\text { Ellipticity } \\
\mathrm{m} / \mathrm{M}\end{array}$ & Phase $\left(^{\circ}\right)$ & Orientation $\left(^{\circ}\right)$ \\
\hline A & 4 & -3.0 & 60.3 & -0.050 & 58.9 & 119.4 \\
B & 4 & 1.2 & 48.6 & 0.025 & 72.6 & 116.7 \\
B & 7 & -3.2 & 41.9 & -0.076 & 67.9 & 136.1 \\
C & 4 & 0.1 & 42.1 & 0.002 & 68.2 & 128.0 \\
C & 9.5 & 0.4 & 33.4 & 0.012 & 61.4 & 136.9 \\
F & 4 & -2.9 & 47.8 & -0.061 & 79.9 & 84.3 \\
\hline
\end{tabular}

TABLE 4. - Tidal ellipse characteristics of the semi-diurnal spectral band at stations A, B, C, and F (February 21 to 23,1990). The rotary coefficient ranges from -1 , clockwise motion, to 1 , anticlockwise motion: $-1<r<1$.

\begin{tabular}{lcccccc}
\hline Station & Depth $(\mathrm{m})$ & $\mathrm{m}(\mathrm{cm} / \mathrm{s})$ & $\mathrm{M}(\mathrm{cm} / \mathrm{s})$ & Orientation $\left(^{\circ}\right)$ & Rotatory Coefficient & Stability Coefficient \\
\hline A & 4 & -3.1 & 58.7 & 118.1 & -0.106 & 0.998 \\
B & 4 & 1.0 & 44.9 & 117.6 & 0.045 & 0.997 \\
B & 7 & -3.8 & 38.2 & 135.9 & -0.015 & 0.986 \\
C & 4 & -0.3 & 38.1 & 128.1 & 0.999 \\
C & 9.5 & 0.8 & 30.5 & 136.6 & -0.123 & 0.997 \\
F & 4 & -2.7 & 43.0 & 265.1 & & 0.999 \\
\hline
\end{tabular}


TABLE 5. - Semi-major axis of the tidal ellipse $(\mathrm{cm} / \mathrm{s})$ for different stations and periods. $\mathrm{Z}_{\mathrm{o}}$ is the vector average of the current observations and $\mathrm{M}_{\mathrm{sf}}$ is the semi-monthly constituent.

\begin{tabular}{|c|c|c|c|c|c|c|c|c|c|}
\hline Station & Period & Days & Precipitation & $\mathrm{Z}_{\mathrm{O}}$ & $\mathrm{M}_{\mathrm{sf}}$ & $\mathrm{K}_{1}$ & $\mathrm{O}_{1}$ & $\mathrm{M}_{2}$ & $\mathrm{~S}_{2}$ \\
\hline MJ & $20 / 5-11 / 7 / 88$ & 53 & rainy & 19.1 & 10.0 & 2.1 & 1.6 & 7.6 & 0.8 \\
\hline MJ & $22 / 10-18 / 12 / 88$ & 58 & rainy & 11.4 & 10.0 & 2.7 & 1.3 & 8.2 & 2.4 \\
\hline $\mathrm{CB}$ & $15 / 1-14 / 5 / 88$ & 121 & dry-rainy & 2.7 & 1.4 & 1.1 & 1.4 & 9.5 & 0.7 \\
\hline $\mathrm{CB}$ & $21 / 10-30 / 11 / 88$ & 41 & rainy & 5.5 & 3.9 & 4.6 & 3.1 & 11.5 & 1.6 \\
\hline IP & $7 / 3-8 / 4 / 88$ & 33 & rainy & 5.1 & 13.4 & 19.9 & 16.6 & 42.3 & 6.8 \\
\hline IP & $3 / 6-9 / 7 / 88$ & 36 & dry-rainy & 12.4 & 6.6 & 42.7 & 22.9 & 54.3 & 6.0 \\
\hline BJ & $7 / 3-31 / 5 / 88$ & 86 & rainy & 5.6 & 1.1 & 7.9 & 3.9 & 23.1 & 3.6 \\
\hline BJ & $5 / 5-28 / 6 / 90$ & 55 & rainy & 2.1 & 0.7 & 7.7 & 3.0 & 20.6 & 3.6 \\
\hline MG & $1-26 / 3 / 84$ & 26 & dry & 20.4 & 2.3 & 4.5 & 0.5 & 0.4 & 1.3 \\
\hline MG & $26 / 4-31 / 5 / 84$ & 35 & rainy & 21.7 & 1.9 & 1.3 & 0.8 & 0.6 & 0.3 \\
\hline MG & $1 / 6-20 / 7 / 84$ & 50 & dry & 15.2 & 4.9 & 0.9 & 0.6 & 0.3 & 0.7 \\
\hline MG & $18 / 10-11 / 84$ & 28 & rainy & 12.6 & 2.7 & 1.0 & 0.9 & 0.8 & 0.3 \\
\hline LO & $17 / 1-25 / 2 / 86$ & 40 & dry & 10.5 & 5.2 & 1.3 & 0.6 & 1.1 & 0.6 \\
\hline
\end{tabular}

tion $\mathrm{C}$ the contribution of the semi-diurnal band is $85.1 \%$ and the contribution of the diurnal band is $9.3 \%$. The stability of the ellipse semi-major axis is very high for the semi-diurnal band (Table 4). The length of the time series at stations $\mathrm{A}, \mathrm{B}, \mathrm{C}$, and $\mathrm{F}$, however, is too short to examine the energy contained at lower frequencies. The analysis will be done below for station BJ (Table 5) which is located near these stations.

Table 4 shows the ellipse parameters and the rotation coefficient in the spectral semi-diurnal band $(0.0833 \mathrm{cph})$. The results illustrate a dominant semidiurnal current (69 to $85 \%$ ), with a minor energetic diurnal constituent (5 to $18 \%$ ). The rotary coefficient illustrates the same behavior as derived from the ellipticity obtained using the harmonic analysis. The ellipse orientation and the semi-major/semiminor axes for the semi-diurnal spectral band have very similar values to those obtained for the $\mathrm{M}_{2}$ constituent in the harmonic analysis. Both results confirm the influence of stratification on the threedimensional current structure.

\section{Impact of tidal motion on residual circulation and mixing}

The transport of salt, nutrients, and pollutants from Maracaibo Strait to Lake Maracaibo must be closely related to the development and decay of stratification within the estuary. The stratification itself is controlled by winds and tides (short term), and by fresh water discharge within the basin (long term), in what is certainly a rather complex interactive process. Table 5 summarizes the results of the harmonic analysis for several stations within the estuarine system, for periods of different precipitation in the basin.
The stations in the Gulf of Venezuela (stations MJ and $\mathrm{CB}$ ) present mixed semi-diurnal tidal currents. The diurnal and semi-diurnal constituents increase southwards, from the entrance to the Gulf of Venezuela (station MJ) to El Tablazo Bay (station IP). In the southern tip of the Gulf (station CB), as well as in El Tablazo Bay and the Strait of Maracaibo (station $\mathrm{BJ})$, the residual current is relatively small as compared with the tidal current. The stations in Lake Maracaibo present mixed diurnal tidal currents but the diurnal and semi-diurnal oscillations are very small. A considerably large semimonthly oscillation is present in the estuarine system. This oscillation has no direct astronomical origin, being very likely caused by non-linear tidal interaction.

Figure 2 shows the results of the spectral analysis for stations IP and BJ during two similar periods, illustrating the dominance of the semi-diurnal current. This figure also illustrates how the spectrum changes at IP from March to June. In March the semi-diurnal band is more energetic, whereas in June the diurnal band dominates. This may be related to the reduction of the trade winds during the May-November period and the consequent predominance of the sea-land breezes, making it logical to expect that the dynamic response of the water body will be at this frequency.

Figure 3 presents two density sections across the navigation channel (mean depth $13 \mathrm{~m}$ ) between El Tablazo Bay (station T41) and the southern end of the Strait of Maracaibo (station B94) from north to south (Figure 1), during ebb tide and flood tide conditions. The conductivity, temperature and currents were recorded at 4, 7 and 9 meters depth at nine stations separated by some 5 to $8 \mathrm{~km}$. From these sections it seems clear that there is significant longitudinal water advection with the tide, such that by the 


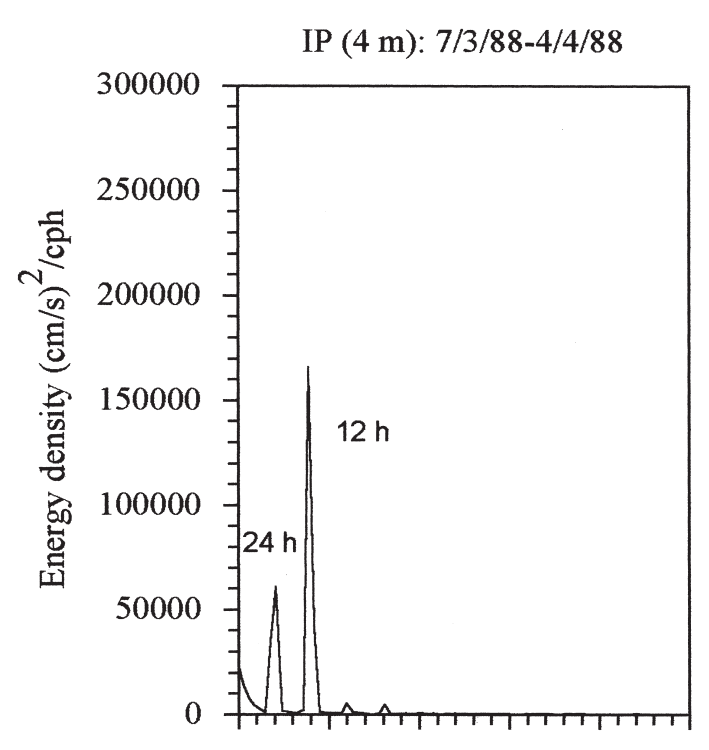

BJ (4 m): 4/4/88-2/5/88

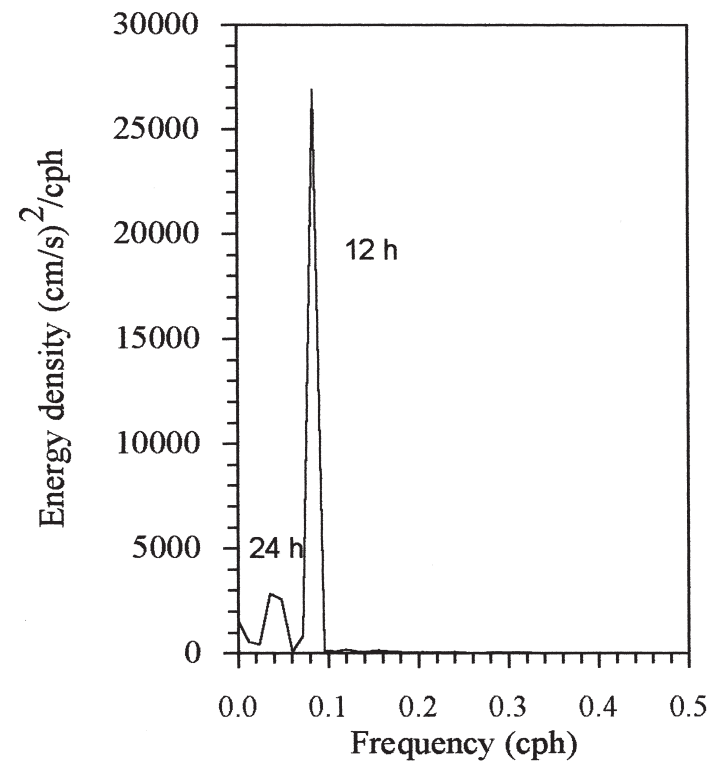

IP (4 m): 3/6/88-1/7/88

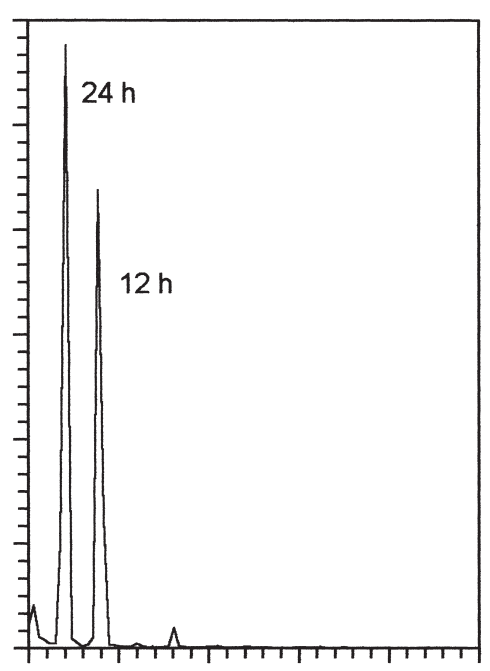

BJ (4 m): 2/5/88-31/5/88

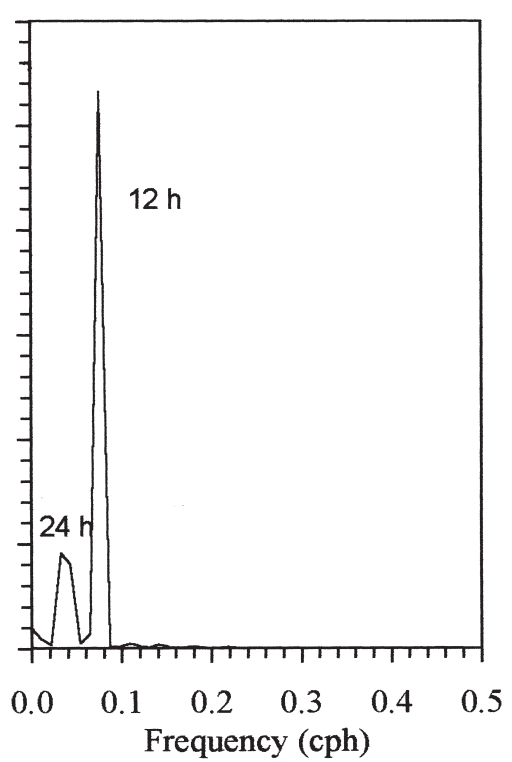

FIG. 2. - Spectral analysis of stations IP, located in El Tablazo Bay, and BJ, located at the southern extreme of the Strait of Maracaibo.

end of the ebbing water the density has decreased considerably in El Tablazo Bay. Another characteristic is the existence of a wedge of relatively dense water that appears at the northern position after the flooding tide and probably propagates along the navigation channel in the Maracaibo Strait. Tidal straining caused by shear in the velocity profile leads to the large variation in stratification during the tidal cycle: for example, current velocities in station T49 are 54, 41 and $19 \mathrm{~cm} / \mathrm{s}$ during the ebb tide, and 16, 11 and $7 \mathrm{~cm} / \mathrm{s}$ during the flood tide, from top to bottom. The surface water travels faster, and makes a longer trajectory, than the near-bed water. On the ebb tide relatively fresh water in the upper portion of the water column has a northward differential displacement and stratification increases. On the flood tide the differential movement will tend to diminish the stratification. Tidal straining can thus be a main control on the strength of the stratification through differential buoyancy input. Figure 3 also suggests the possibility of periodic mixing within the Strait of Maracaibo. Such periodic destratification would modify the tidal ellipses, as we observed at stations $\mathrm{A}, \mathrm{B}, \mathrm{C}$ and $\mathrm{F}$, and reduce the water exchange with Lake Maracaibo. Since instability and mixing is proportional to the square of the velocity difference between both layers, we may expect that the tidal oscillation, in conjunction with 
river discharge, will be the principal factor responsible for vertical mixing.

The surface current at station MG, in the southeastern portion of the Lake, flows to the north-northeast (Fig. 4), while the surface current at station LO, near the center of Lake Maracaibo, flows west-southwest (Fig. 5). The representation of the North-South and East-West components in a scatter plot confirms the anticlockwise circulation model proposed for the lake (Redfield et al., 1955). The temporal series at both stations show long period oscillations. The results of the harmonic analysis at these stations (Table 5) confirm the relative importance of the fortnightly Msf constituent, this being higher at LO than at MG.

The character of the semi-monthly oscillations in the lake, likely of non-linear tidal origin, is shown by the current velocity time series recorded at several depths at station LO, during the dry season (Fig.
6). The oscillations at the surface and at $10 \mathrm{~m}$ depth have almost the same amplitude and are in phase. At $20 \mathrm{~m}$ depth the oscillations are somewhat damped, but remain in phase with the surface movements. The regularity of this oscillation suggests a tidal rather than a meteorological origin.

We have employed the rotary spectral analysis of surface current data from the Lake to examine the possible importance of non-linear higher harmonics or other factors. Figure 7 shows the rotary spectra (clockwise and anticlockwise contributions) at stations LO, near the center of the lake, and MG, located at the southeastern zone. Both $S^{-}$and $S^{+}$are plotted as functions of frequency magnitude, $|f| \geq 0$, with solid and dashed lines corresponding to the clockwise and anticlockwise spectra, respectively. The semi-diurnal and diurnal periods are predominantly clockwise at both stations. The results illus-
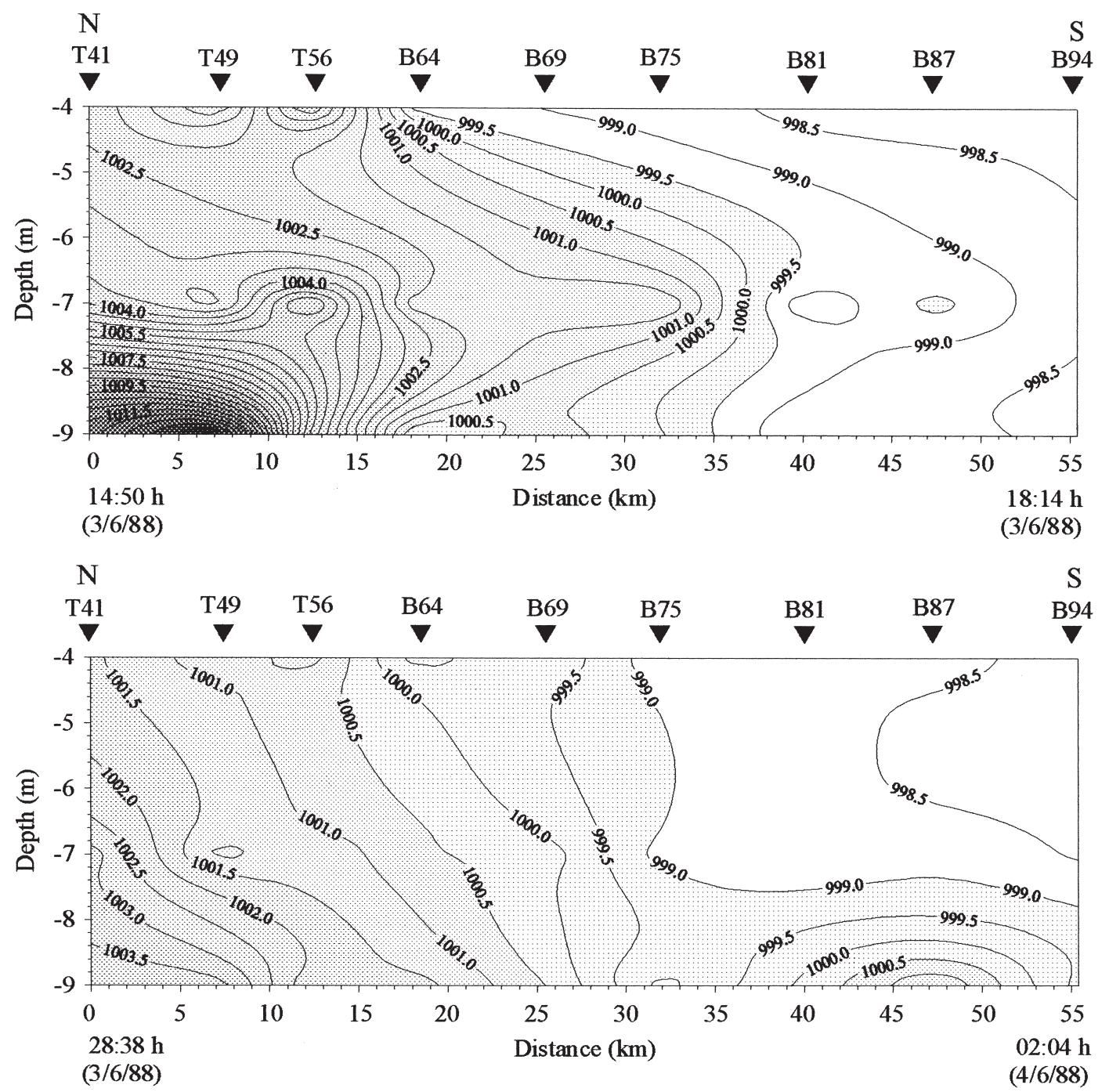

FIG. 3. - Longitudinal density section $\left(\mathrm{kg} / \mathrm{m}^{3}\right)$ from El Tablazo Bay (T41) to the southern end of the Strait of Maracaibo (B94), during ebb tide (upper figure) and flood tide (lower figure) conditions. 

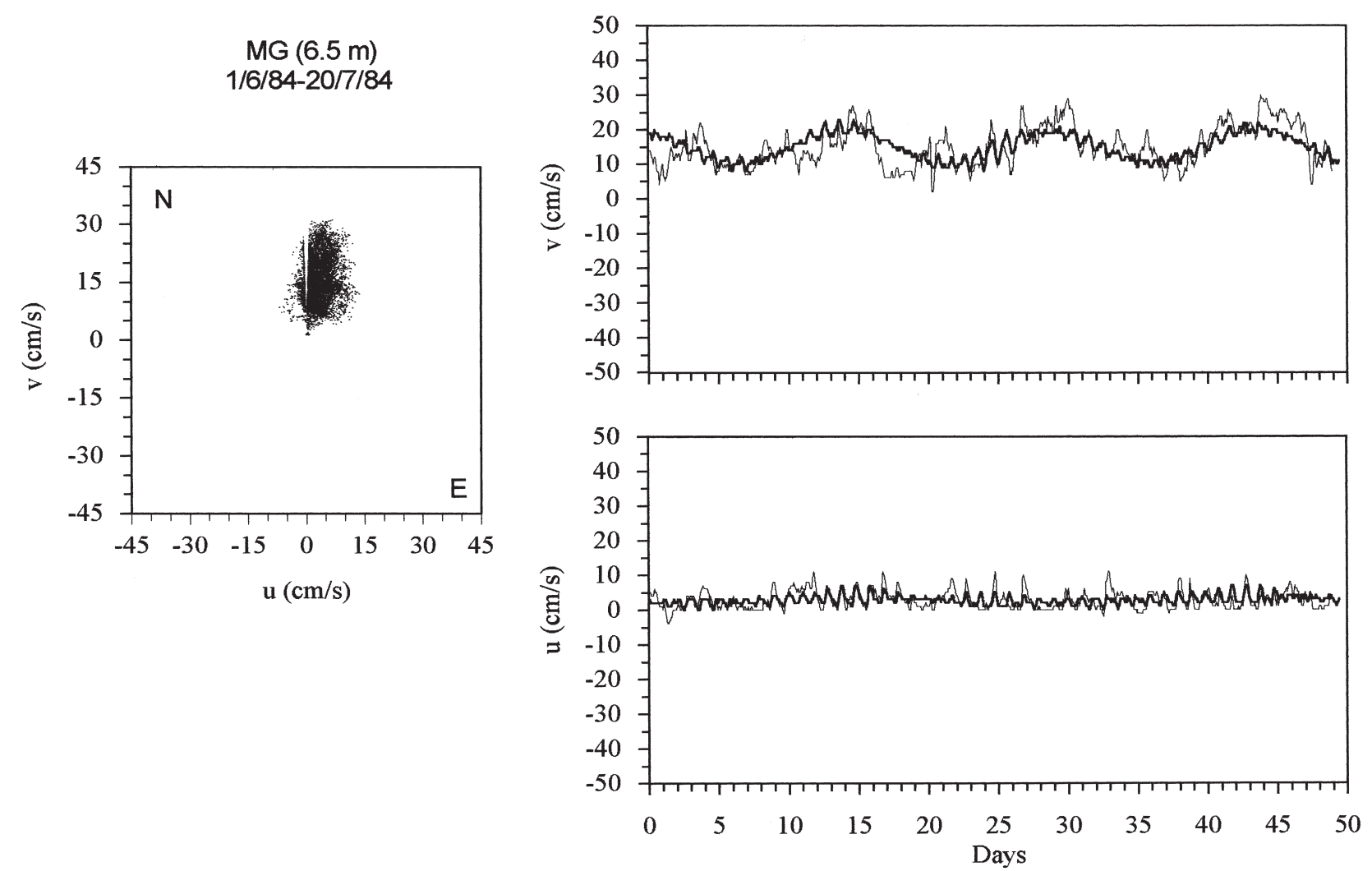

FIG. 4. - Representation of the North-South (v) and East-West (u) components of the current velocity at station MG, both as a scatter plot and as a time series. The thin line corresponds to measured values and the thick line to tidal current predictions.
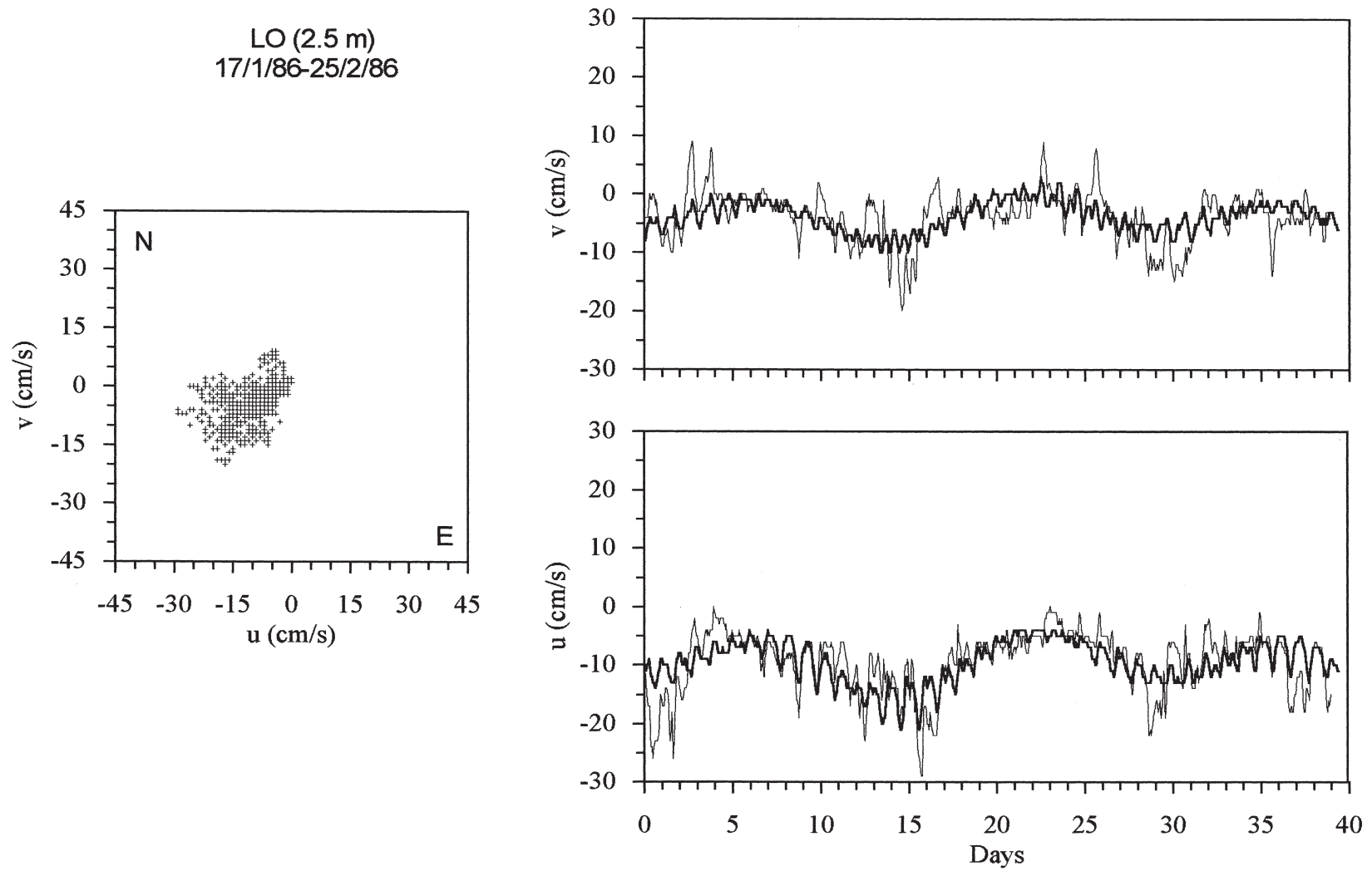

FIG. 5. - Representation of the North-South (v) and East-West (u) components of the current velocity at station LO, both as a scatter plot and as a time series. The thin line corresponds to measured values and the thick line to tidal current predictions. 
trate the existence of a near-inertial peak in the clockwise spectra at both stations. The observed periods are higher than the local theoretical inertial period, approximately 69 hours $(0.0145 \mathrm{cph})$, at station LO (0.0133 cph) and lower in MG station $(0.0178 \mathrm{cph})$. There are many possible ways in which the period of inertial movements may be modified. The observed inertial period may be affected by the presence of stratification, the process of wave propagation, or the existence of horizontal velocity gradients (Gonella, 1971). The energy at the near-inertial band is somewhat smaller near the
Lake shore because of the inhibition of inertial currents at the boundary.

The results also point to the importance of the semi-monthly oscillation, Msf, principally clockwise at LO and anticlockwise at MG. The large amplitude of the semi-monthly constituent at LO may be influenced by stratification caused by fresh water discharge into the system. The isolated peak at the frequency $0.0067 \mathrm{cph}$ (149 hours) in station MG could perhaps be a Kelvin type wave, similar to the basin scale motion described by Saggio and Imberger (1998) for Lake Biwa.
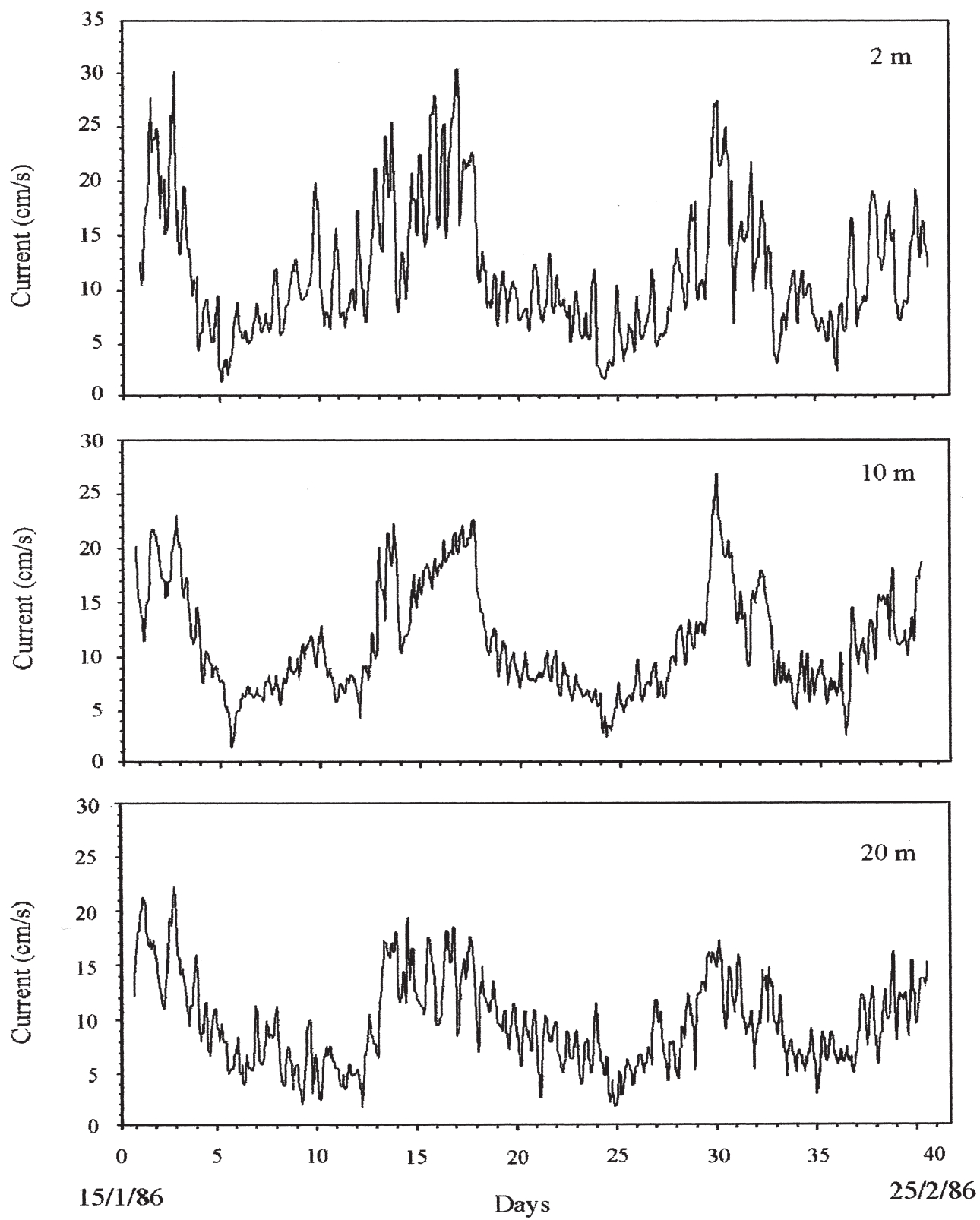

FIG. 6. - Times series of the current velocity at 2, 10, and 20 m depths at station LO (after Pelegrí et al., 1986). 
$\mathrm{LO}(2.5 \mathrm{~m})$

$17 / 1 / 86-13 / 2 / 86$

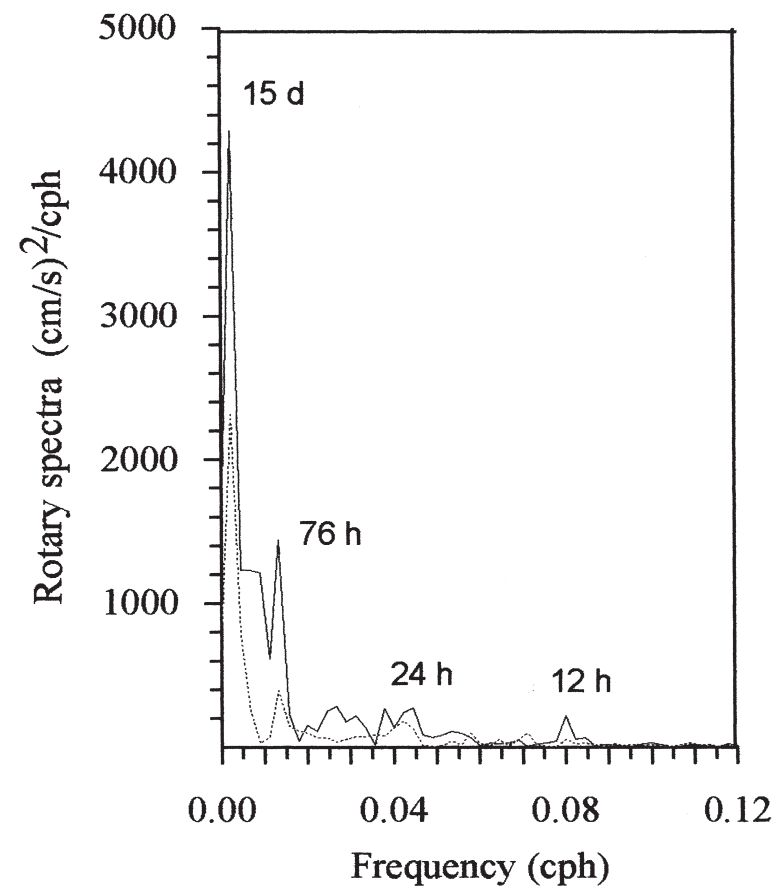

MG (6.5 m)

26/4/84-21/6/84

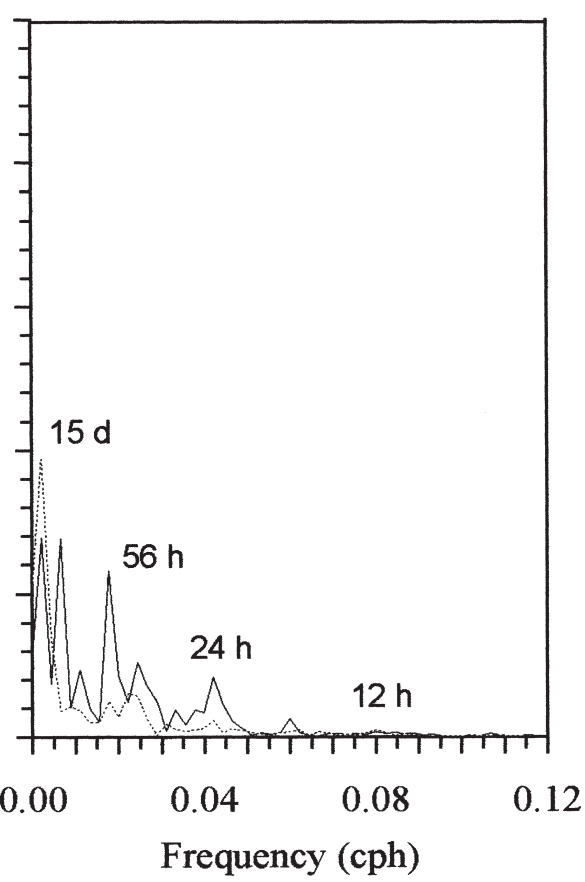

FIG. 7. - Rotary spectral analysis at stations LO, near the center of the Lake, and MG, in the southeastern zone. Solid and dashed lines correspond to the clockwise and anticlockwise components, respectively.

\section{CONCLUSIONS}

The analysis of current time series shows that the tide, and its interactions with other phenomena such as winds and fresh water discharge, is the dominant source of current variability in the Lake Maracaibo estuarine system. This variability controls the entrance of salt water to the Lake and provides a mechanism for periodic exchange within the water column. The results indicate that water mass exchange may be associated with different time scales: semi-diurnal, diurnal, and longer periods, such as semi-monthly and monthly.

Tidal oscillation is the main factor responsible for periodic stratification and mixing within the Strait of Maracaibo. The spatial stratification and its short-term variability plays a role in the resulting tidal ellipses, in particular making the surface and bottom layers rather uncoupled. This situation may be particularly evident during some phases of the semi-monthly spring-neap cycle, probably because of the relation of mixing and the intensity of tidal currents.

Non-linear interactions appear to be very important within Lake Maracaibo, and may be responsible for the generation of residual currents. The semi- monthly oscillation in Lake Maracaibo could be due to the interaction between the incoming tide and the outgoing fresh water flow, in the fashion suggested by Godin (1991) as a barotropic non-linear interaction; or a baroclinic non-linear interaction where density variations are important. In Lake Maracaibo other motions such as inertial and Kelvin type movements may also be present.

Although the general circulation in the Lake Maracaibo estuarine system is rather well known, the small-scale processes that determinate the mass exchange at the entrance to the Lake and into the hypolimnion demand a more accurate description. The dynamics of this enclosed system is rather unique, with water bodies interacting among themselves and responding to external forcing, suggesting a nearly ideal laboratory to study many different physical processes.

\section{ACKNOWLEDGEMENTS}

The authors wish to thank PDVSA for making their data available during a visit of A.M.A. to the institution with financial assistance from INTEVEP and the University of Las Palmas de Gran Canaria. 
The authors also thank Mercedes Escaples and Iván Galindo for making possible to participate in the "Ecological Evaluation of the Maracaibo Lake" project, and Germán Febres for a number of interesting suggestions and constructive discussions.

\section{REFERENCES}

Godin, G. - 1991. Frictional effects in river tides. In: B.B. Parker (ed.), Tidal Hydrodynamics, pp 379-402. John Wiley \& Sons, New York.

Gonella, J. - 1971. A local study of inertial oscillations in the upper layers of the ocean. Deep-Sea Res., 18: 775-788.

LeBlond, P.H. - 1991. Tides and their interactions with other oceanographic phenomena in shallow water. In: B.B. Parker (ed.), Tidal Hydrodynamics, pp 357- 378. John Wiley \& Sons, Inc, New York.

Lynch, D.R., F.E. Werner, J.M. Molines and M. Fornerino. - 1990. Tidal dynamics in a coupled ocean/lake system. Estuar. Coast. Shelf Sci., 31: 319-343.

Masciangioli, P, J.L.Pelegrí and R. Ávila. - 1984. Breve descripción de las corrientes, mareas, vientos y oleaje en la Bahía El Tablazo. Informe interno, INTEVEP.

Molines, J.M. and M. Fornerino. - 1985. Proyecto de Investigación: Circulación en el Lago de Maracaibo. Convenio LUZICLAM. La Universidad del Zulia, Facultad de Ingeniería, Departamento de Hidráulica. 152 pp.

Molines, J.M., M. Fornerino and C. Le Provost. 1989. Tidal spectroscopy of a coastal area: Observed and simulated tides of the Lake Maracaibo System. Cont. Shelf Res., 9: 301-323.
Parker, B.B. 1991. The relative importance of the various nonlinear mechanisms in a wide range of tidal interactions. In: B.B. Parker (ed.), Tidal Hydrodynamics, pp 237-268. John Wiley \& Sons, Inc. New York.

Parra-Pardi, G. - 1983. Cone-shaped hypolimnion and local reactor as outstanding features in eutrophication of Lake Maracaibo. $J$. Great Lakes. Res, 9: 439-451.

Pelegrí, J.L., P. Masciangioli, C. Villoria, R. Avila and B. Alonso. 1986. Mediciones de Corrientes y Vientos en Planta Lama, Lago de Maracaibo. INT-01629,86. Departamento de Tecnología de Producción. Sección de Estudios Ambientales. Unidad de Meteorología y Oceanografía. INTEVEP. PDVSA. 45 pp.

Pelegrí, J.L. and P. Masciangioli. - 1987. Predicción de corrientes en Puerto Miranda. Tablas para 1987. Departamento de Tecnología de Producción. Sección de Estudios Ambientales. Unidad de Meteorología y Oceanografía. INT-EPTP-00015,87. INTEVEP. PDVSA. 204 pp.

Pelegrí, J.L., R. Ávila, C. Villoria and P. Masciangioli. - 1988. Condiciones Hidrográficas en la Bahía El Tablazo y el Estrecho de Maracaibo. Informe Técnico INTEVEP S.A., INTEPTP-00012, 88. $167 \mathrm{pp}$.

Redfield, A.C. B.H. Ketchum and D.F. Bumpus. - 1955. The hydrography of Lake Maracaibo, Venezuela. Report to Creole Petroleum Corporation, Unpubl. Manuscript Ref. 55-59. Woods Hole Oceanographic Institution. 152 pp.

Redfield, A.C. - 1961. The tidal system of the Lake Maracaibo, Venezuela. Limnol. Oceanogr., 6: 1-12.

Saggio, A and Imberger, J. - 1998. Internal wave weather in a stratified lake. Limnol. Oceanogr., 43: 1780-1795.

Sutton, E.A et al. - 1974. Study of effects of oil discharges and domestic and industrial wastewaters on the fisheries of Lake Maracaibo, Venezuela. Vol. I. Ecological Characterization and Domestic and Industrial Wastes. Ed. W. L. Templeton, Battelle Pacific Northwest Laboratories. Report to Creole Petroleum Corporation. 175 pp. 